\title{
Comunicación

\section{Los medios de comunicación}

como fuente de información en la construcción de representaciones sociales de la delincuencia

Media as a source of information in the construction of social representations

El objetivo del artículo es proponer el método utilizado para explorar las fuentes de información en la construcción de representaciones sociales sobre delincuencia. Los resultados de la investigación arrojaron tres tipos de fuentes: las intrapersonales, interpersonales y las masivas. La credibilidad, frecuencia y accesibilidad a cada fuente fueron los factores más relevantes para determinar la importancia de cada una de ellas.

PALABRAS CLAVE: Representaciones sociales, medios de comunicación, estudios culturales de audiencia, fuentes de información, métodos cualitativos.

This article aims to discuss the methodology applied to explore the role of different sources of information in the construction of social representations on delinquency. Results show three types of sources of information: intrapersonal, interpersonal and massive. It was possible to find out that three elements determine the importance of each source: credibility, frequency and accessibility.

KEYWORDS: Social representations, media, cultural studies audience research, sources of information, qualitative methodology.

1 Universidad de Monterrey, México.

Correo electrónico de correspondencia: beatriz.inzunza@udem.edu

Fecha de recepción: 01/07/2016. Aceptación: 09/11/2016. 


\section{INTRODUCCIÓN}

Entrevistadora: Vamos a hacer un segundo dibujo. En esta ocasión, el dibujo que te voy a pedir es de alguien como los zetas que acabas de mencionar.

Katy: [Empieza a dibujar] Yo antes me los imaginaba como Homero Simpson.

Entrevistadora: ¿Como Homero Simpson?, ¿por qué?

Katy: Porque a mí me decían que Homero Simpson era malo. A mí no me dejaban ver Los Simpsons porque "no era para niños". Y de hecho, no es para niños.

(Katy, niña, MA-A). ${ }^{2}$

Ante una situación de conflicto, el individuo acude a la construcción de representaciones sociales para reducir la sensación de amenaza o miedos (Jovchelovitch, 2001). Este artículo presenta un fragmento de un estudio realizado durante los años 2012-2014, cuyo objetivo fue explicar las fuentes de información que los niños entre 9 y 12 años utilizaron para la construcción de sus representaciones sociales sobre inseguridad y delincuencia, en Monterrey, México (Inzunza, 2014).

En un contexto donde los índices de criminalidad estaban en constante aumento debido a conflictos entre grupos organizados y gobierno, la agenda de los medios se encontraba saturada de información relacionada con la inseguridad, y donde las escuelas y colegios se vieron en la necesidad de realizar simulacros en caso de balaceras, resultó importante estudiar cómo comprendían los niños del municipio de San Pedro Garza García del área metropolitana de Monterrey, el tema de delincuencia en la ciudad. Para ello, se llevaron a cabo 45 entrevistas a niños que pertenecían a familias con nivel socioeconómico medio alto y medio bajo, de manera que pudiera hacerse un comparativo de representaciones sociales y fuentes de información entre ellos.

2 Los códigos para identificar a cada uno de los participantes en las citas textuales se conforman de la siguiente manera: pseudónimo elegido por los mismos participantes, sexo y nivel socioeconómico: medio alto-alto (MA-A) y medio bajo (MB). 
El objetivo de este artículo es, en primer lugar, mostrar la compatibilidad de la Teoría de Representaciones Sociales (TRS) y los estudios culturales de audiencia, debido a que muchos de sus sistemas de lógica y conceptos se complementan. En segundo lugar, compartir la propuesta metodológica que pretendió explorar ambas teorías dentro del estudio. Y finalmente, hacer un análisis del papel que tienen los medios de comunicación masiva en relación con otras fuentes de información.

Respecto de la propuesta metodológica, es importante adelantar que de forma previa se utilizaron dos técnicas: la dinámica de dibujos durante la entrevista focalizada y la creación de narrativas. Dos estudios fueron fuente de inspiración para utilizar esta metodología: Lemish y Götz (2007) y Bar-Tal y Teichman (2005).

En el desarrollo de la metodología se buscó probar como nuevas estrategias:

1. La detonación del tema de inseguridad en niños, sin hacer una mención explícita del tópico. Esto, además de facilitar la autorización de las instituciones educativas y padres de familia, permitió conocer el tópico en la mente de los niños de una manera más genuina.

2. La confrontación de términos, la cual permitió conocer los significados que se depositan en algunos conceptos que los niños utilizan, independientemente de estar conscientes de su definición o no.

\section{PUNTOS DE ENCUENTRO ENTRE LOS ESTUDIOS CULTURALES}

\section{DE AUDIENCIA Y LA TEORÍA DE REPRESENTACIONES SOCIALES}

La TRS y los estudios culturales de audiencia son, desde sus diferentes disciplinas, muy compatibles. Mientras que la primera se apoya de conceptos provenientes de la psicología social, la segunda es interdisciplinaria. Tener este carácter es además conveniente para los media studies, dado que necesitan de otras aproximaciones teóricas y metodológicas para llevar a cabo sus investigaciones.

Primeramente, es necesario precisar que las representaciones sociales no solo se refieren a una imagen (como lo sería un imaginario), sino también a una serie de juicios e ideas que influyen en el comportamiento del individuo (Araya, 2002). Moscovici (2001) habla además de una 
función de colectividad de dichas representaciones sociales, puesto que el comportamiento no solo es influido por ellas, sino por una especie de "contrato social" que existe en la colectividad donde se desenvuelve. El mismo autor indica que este contrato social se establece y refuerza constantemente en esa determinada sociedad gracias a los líderes de opinión (políticos, curas, educadores, medios de comunicación, entre otras instituciones).

Para la TRS, la construcción social y la comunicación son fundamentales, y es por eso que el triángulo psicosocial entre ego (sujeto), álter y objeto es central para explicar la construcción -y reconstrucción- de las representaciones sociales. En este esquema, "objeto" es aquello alrededor de lo cual se construye la representación social, es lo que se busca comprender y adoptar como parte de la realidad del individuo. "Álter" se refiere a las fuentes de información con las que el "sujeto" interactúa, y tiene como consecuencia la construcción, modificación o actualización de las representaciones sociales (Araya, 2002). Por lo mismo, al momento en que se realizó el estudio, era prácticamente imposible que un solo mensaje hubiese sido la referencia absoluta de la representación social en el tema de inseguridad. Es decir, se partió de la premisa de que cada uno de los sujetos entrevistados, habían ya interactuado con diferentes álteres que permitieron la complejidad y a su vez diversidad en las representaciones sociales, pese a mencionar los mismos objetos (inseguridad y delincuencia).

Aun y cuando los participantes hubiesen estado expuestos a los mismos álteres -a los cuales se les llamará fuentes de información en este texto-, los estudios culturales de audiencia hablan del concepto de "mediaciones", las cuales complejizan el proceso de recepción de un mensaje. Se entienden por mediaciones a "las instancias estructurantes de la interacción de los miembros de la audiencia, que configuran particularmente la negociación que realizan con los mensajes e influyen en los resultados del proceso" (Orozco, 1991, p. 74). De acuerdo con el mismo autor existen mediaciones de tipo individuales, como sexo, edad, capacidad cognitiva, bagaje cultural, educación, nivel socioeconómico; institucionales, como familia, religión, trabajo, escuela, medios de comunicación; situacionales, que rodean el espacio y tiempo de recepción, y video-tecnológicas, respecto de la tecnología del aparato 
en que se transmite el mensaje. Todas estas mediaciones influyen en la forma en que se "negocia" el mensaje.

Otro concepto importante que se maneja en los estudios culturales de audiencia, es el de representación. Según Barker (2008), "los textos, como forma de representación, son polisémicos. Es decir, contienen la posibilidad de un número de diferentes significados que tienen que ser creados por los lectores quienes les dan vida a las palabras e imágenes" (p. 11). Es gracias a esta característica que se considera la posibilidad de una audiencia activa - puesto en palabras de Barker (2008)- en la que estas no representan ineptos culturales, sino productores activos de significados desde sus propios contextos culturales.

El problema de la representación de la realidad está relacionado con la intención de que ciertos textos mediáticos tienen que ser "realistas", como los noticieros y documentales. Independientemente de que un programa sea realista o no, siempre involucra un proceso de representación, por lo que resulta importante que en estudios como el que se presenta en este artículo, busquen la brecha que existe entre la "realidad" y la "representación mediática" (Götz, comunicación personal, 24 de julio de 2014).

Particularmente, los estudiosos de las representaciones sociales enfatizan con frecuencia la necesidad de observar los medios porque constituyen una parte inevitable en los procesos de construcción de las representaciones sociales en los individuos. Por ejemplo, Wagner y Kronberger (2001) indican su importancia en la consolidación de las representaciones sociales, pero también hablan de las conversaciones interpersonales que legitiman los discursos mediáticos. El valor de esta propuesta metodológica reside precisamente en la consideración no solo de los medios de comunicación masiva, sino de otros procesos comunicativos (inter e intrapersonales) en la comprensión de la realidad que expresan los participantes.

Es precisamente la perspectiva compleja de esta "negociación" de significados, y por lo tanto de imaginarios y actitudes, lo que ambas teorías defienden. Los puntos de encuentro residen en que los procesos de construcción de representaciones sociales hablan de cómo el individuo -en su rol de audiencia, por ejemplo-activamente las crea, 
modifica y actualiza, eligiendo -con base en distintos factores de la persona- las fuentes de información que satisfagan sus necesidades e intereses.

\section{PROPUESTA METODOLÓGICA: CUESTIONAMIENTO DE FUENTES}

La metodología fue de carácter cualitativo, se utilizó la entrevista focalizada con el apoyo de la técnica de dibujos. A través de cuatro instituciones, se llevaron a cabo 45 entrevistas de manera individual a niños entre 9 y 12 años de edad (sexto grado de primaria). Dos instituciones cuentan con alumnado que pertenece a un nivel socioeconómico medio bajo (donde se realizaron 22 entrevistas), mientras que las otras dos tienen alumnos que integran el nivel medio alto o alto (23 entrevistas).

Dado que se firmaron convenios de anonimato, no se pueden indicar cuáles fueron las instituciones visitadas, pero es importante mencionar que se contactaron más de las que aceptaron participar. En general, se presentó un alto grado de rechazo a colaborar con este proyecto de investigación, debido a que los padres de familia o directivos evitaban abordar el tema de crimen y delincuencia con los menores de edad. Es importante enfatizar que si bien todas las instituciones se ubicaban en el municipio San Pedro Garza García, no todos los participantes habitaban en él al momento de llevar a cabo la entrevista.

Otra anotación; la autora es la responsable de esta investigación, puesto que es quien llevó a cabo su diseño, los contactos, las transcripciones y el reporte de resultados en diversos tipos de documentos. Sin embargo, para fines de cumplir con algunas indicaciones de dos de las instituciones, participaron otros tres investigadores como entrevistadores. Esto debido a que ciertas entidades permitieron el acceso durante un tiempo y fechas limitadas. Con el apoyo de los colegas, fue posible realizar la cantidad de entrevistas previstas en el tiempo que indicaron las escuelas participantes.

La dinámica de la sesión consistió en, primero, detonar el tema de inseguridad y delincuencia. Para fines de disminuir la preocupación de los padres de familia y maestros, en cuanto a que pudieran ser depositadas ideas de violencia o información que consideraban no apta para su edad, se partió de la premisa de que si los niños no respondían a las 
siguientes preguntas, mencionando algo de los tópicos en cuestión, se daría por terminada la entrevista:

1. Imagina que estás con alguien que no conoce México... ¿Qué le podrías decir acerca de tu país?

2. Y si te pregunta por Monterrey, ¿qué le contarías?

3. Y si te pregunta cómo está la situación, ¿qué le dirías?

4. ¿Ves noticieros? ¿De qué hablan normalmente?

5. ¿Hay algo que te preocupe de lo que dicen los noticieros o tus papás de lo que pasa en Monterrey? ¿Por qué?

Esto, además de facilitar la autorización de los padres de familia para entrevistar a los niños participantes, también permitió que se abordara el tema de una manera más auténtica. Es importante anotar que no hubo necesidad de cancelar ninguna entrevista (en 45 niños), y que en la mayoría de las ocasiones se detonó con la pregunta 3. Una vez que surgía el tema de inseguridad y delincuencia, se pasaba directamente a la siguiente sección de la entrevista.

Las siguientes etapas de la entrevista se llamaron "Situación de inseguridad", que buscaba conocer en qué crímenes pensaban al momento de hablar de inseguridad, así como una descripción amplia del escenario: lugares, horas, personajes, narrativas (qué pasó antes y qué después del momento dibujado), y "El delincuente", cuyo propósito fue el de conocer los estereotipos en torno al criminal, y que se cuestionaba sobre su apariencia y rasgos físicos, personalidad, hábitos, discursos, relaciones sociales, espacios y biografía. En ambas secciones de la entrevista, se inició pidiendo que dibujaran una escena de inseguridad y también a un delincuente. Una vez avanzado el dibujo, se les hicieron preguntas que permitían conocer las representaciones sociales de los niños en ambas cuestiones.

Posterior al análisis descriptivo, se dedicaron unas preguntas a reconocer las actitudes frente a las situaciones de inseguridad y los delincuentes. Para ello, se preguntó por qué pensaban que sucedían estos incidentes, cuál es el papel de las autoridades y gobernantes al respecto, qué debería pasar con el delincuente, y qué soluciones deberían implementarse para resolver estas problemáticas. 
Finalmente, cada una de las dos etapas cerraba con el cuestionamiento de fuentes:

1. ¿Dónde has visto que sucedan cosas como las de tu dibujo? O bien, ¿en dónde has visto a personas como las de tu dibujo? ¿Lo viste solo o acompañado con alguien? ¿Te explicaron qué sucedía/quién era y qué hacía? ¿Quién te explicó?

2. ¿Platicas con tus amigos de esto? ¿Cómo te enteras que pasan estos incidentes? ¿Qué opinan de personas como los delincuentes?

3. ¿Has platicado con tus papás acerca de estos incidentes/personas? ¿Qué te han dicho de ellos? ¿Qué creen ellos que deberían hacer las autoridades al respecto?

4. En la escuela, ¿tus maestros, coordinadores o compañeros, platican de estos incidentes o de ellos contigo? ¿Qué te dicen?

5. ¿Has visto alguno tú directamente en la calle o en la ciudad, parecido a tu dibujo? ¿Has sido víctima o testigo de un incidente de violencia?

6. ¿Has visto en la tele a alguno? ¿Qué decían en la tele de esa persona? ¿En qué programa lo viste? ¿Era noticiero, novela o programa?

7. ¿Has visto en periódicos a alguno/algún incidente? ¿Qué era? ¿Quién era? ¿Qué decía de esa persona? ¿Qué explicaba del incidente?

8. ¿Has escuchado en radio algo o a alguien como lo que dibujaste? ¿Has visto en el cine a alguno o algo?

9. ¿Has visto en Internet algo similar a tu dibujo? ¿En qué página? ¿Qué decía al respecto?

10. ¿Has jugado algún videojuego donde aparece alguien o algo similar a tu dibujo?

Estas preguntas abordaron casi todo lo que podían recordar inicialmente los participantes, a excepción de medios impresos como espectaculares en las calles. ${ }^{3}$ El propósito de la pregunta 1 en esta etapa de la

3 El ejemplo que se mencionó, aunque solamente en una ocasión, era propaganda del Partido Verde Ecologista de México (PVEM) que promovía la "Pena de muerte a secuestradores". 
entrevista, consistía en identificar cuáles eran las fuentes que consideraban más importantes en su construcción de representaciones sociales. Se parte de varias premisas para ello: la similitud con el dibujo realizado, la claridad visual, la fascinación o impacto que tuvo la fuente en el participante y lo reciente de la exposición.

La similitud con el dibujo realizado es un tanto evidente porque es lo que el participante estaba imaginando al momento de realizar la pregunta. Si bien sus fuentes de inspiración para la imagen pudieron ser varias, usualmente tenían como base una más importante, y era la que surgía al momento de preguntar esto.

La claridad visual es un elemento importante, puesto que los niños solían dibujar escenarios que comprendían de tal manera que pudieran elaborar una historia y una ilustración al respecto. Por lo mismo, resultaba más complejo elaborar imágenes de crímenes de mayor grado como el narcotráfico, secuestro o extorsión, las cuales se vieron con menor frecuencia, y en cambio se repitieron más retratos de robos a mano armada, que son escenarios que se pueden ver repetidamente en distintos formatos mediáticos, inclusive en dibujos animados dirigidos a audiencias infantiles.

La fascinación o impacto que pudiera haber provocado la fuente sobre el participante es una suposición que se basa sobre todo en los niños que fueron testigos, o que son jugadores asiduos de algún videojuego en específico. ${ }^{4}$ Rodrigo Luna (niño, MA-A), por ejemplo, tenía respuestas detalladas, y narró una experiencia personal donde dos familiares fueron víctimas de secuestro y asesinato (supone que fue a causa del crimen organizado en su estado de origen). Por otro lado, el ejemplo de Bob Esponja (niño, MB), quien realizó el dibujo que suele causar más impacto, muestra el asesinato a cuatro mujeres: dos ahorcadas, una mutilada y otra a punta de pistola. Él mencionó que, pese a no tener el permiso de su madre, jugaba constantemente el videojuego de Grand Theft Auto (GTA).

Por último, respecto de lo reciente de la exposición, se refiere a que se mencionaron fuentes que al momento de la entrevista estaban en

4 El ejemplo más claro fue con la franquicia de Grand Theft Auto (desarrollado por Rockstar North). 
cartelera, o a las que tuvieron acceso en fechas cercanas. Por ejemplo, varios de los niños de nivel socioeconómico medio bajo, mencionaron repetidamente "El Bazucazo" (2010), la cual obtuvieron a través de compra pirata. En ambos niveles socioeconómicos se mencionó con frecuencia a la serie de filmes Rápido y Furioso, cuya sexta edición se estrenó justo el verano en que se empezaron a realizar las entrevistas.

La siguiente etapa fue la de "Confrontación de términos", durante la cual el entrevistador tomó notas para así poder cuestionar sobre los conceptos utilizados por el niño. El concepto de "corrupción" fue el único que se preguntó directamente a todos los participantes, pero algunos otros términos utilizados fueron: sicarios, cárteles, secuestro, violación, narcotráfico. Se cuestionó directamente si sabían lo que significaba, y posteriormente se les pedía "una definición en sus palabras".

El cierre de la entrevista constó de una serie de preguntas sobre la resolución de los conflictos descritos; es decir, cuándo creían que esto podría finalizar, cómo sucedería tal solución, si les gustaría tener más información al respecto, cuál podría ser su contribución en su resolución y cómo se sentían con la situación actual.

El diseño del cuestionario probó ser efectivo, en el sentido que la mayoría de los participantes comprendieron el lenguaje y respondieron con la información requerida. Las confusiones fueron mínimas, y lograron resolverse casi en su totalidad gracias a los entrevistadores. Los problemas presentados al contestar estaban asociados con la memoria, la cual pudo haber sido afectada a su vez por los nervios que evidenciaron algunos informantes.

La etapa de análisis de resultados permitió reconocer nuevas fuentes de información. Por ejemplo, en las narrativas se encontraron clichés televisivos, cinematográficos y de videojuegos, que si bien no fueron explícitamente mencionados por los entrevistados, no fue difícil reconocerlos. Ejemplo de ello, fue una persecución en helicóptero después del robo en un banco, dibujado por Karina (niña, MB); o el caso de un narcobloqueo 5 en la ciudad, elaborado por Cristy (niña,

5 Narcobloqueo es el término designado a los incidentes en los que los miembros del crimen organizado bloquean autopistas o avenidas con el fin de generar caos vial. 
MA-A), que si bien la participante no terminaba de comprender en su totalidad este tipo de incidentes, tenía una claridad visual sobre ello.

Por otro lado, los dibujos se triangularon con colegas en dos universidades mexicanas y una belga, y estudiantes de nivel licenciatura en dos universidades mexicanas y una estadounidense. A través de estas presentaciones, se abrió una discusión sobre las imágenes para así ampliar el análisis a diversas perspectivas. Esto permitió la identificación de nuevas fuentes que no fueron indicadas por los mismos niños, pero que, para otros, fueron fáciles de reconocer en programas televisivos, caricaturas y videojuegos. Tal fue el caso del dibujo de Messi (niño, MB), quien agregó a la Santa Muerte en la escena de asesinato, basándose en el personaje de Grim Reaper de la serie animada de The Grim Adventures of Billy \& Mandy (Atoms, 2003).

Estas estrategias permitieron reconocer diversas fuentes de información que los participantes no mencionaron como tal en las entrevistas, y así integrarlas como parte del análisis de resultados.

\section{EL PAPEL DE LOS MEDIOS RESPECTO \\ DE LAS OTRAS FUENTES DE INFORMACIÓN}

Se identificaron tres tipos de fuentes de información: intrapersonales, interpersonales y masivas. Se entienden por intrapersonales todos los casos en los que los participantes fueron testigos de un incidente de crimen o violencia, puesto que no hubo otro intermediario para enterarse de ello. Se dividen a su vez en dos subtipos: testigo directo, cuando los participantes experimentaron un incidente de violencia o crimen, y testigo indirecto, por ejemplo, Beto (niño, MA-A) quien experimentó el secuestro de un familiar. Los interpersonales son aquellas fuentes que implican un diálogo, como lo son la familia, los amigos y relaciones en la escuela (maestros y compañeros). Las masivas son las fuentes provenientes de los medios de comunicación: periódico, noticieros, radio, programas televisivos, caricaturas, películas, videojuegos, spots publicitarios, entre otros.

Cada uno de los tipos de fuentes tiene una relevancia distinta, dependiendo de la perspectiva desde la cual se analice. Para fines de este estudio, hay tres cuestiones a tomarse en cuenta para evaluar cuál 
podría ser más importante en el proceso de construcción de representaciones sociales: la credibilidad que se le deposita a cada uno de los tipos de fuentes, la frecuencia de exposición hacia cada tipo de fuente y la accesibilidad a ellos.

Para fines de estos hallazgos, se entiende credibilidad como la confianza que tienen los niños en esa fuente de información, y en la entrevista se vio reflejado el poco o mucho cuestionamiento que los niños hicieron al respecto. La frecuencia es el número de veces en determinados periodos (según cada participante) al que se expone ante la fuente de información, según se indique. Y finalmente, la accesibilidad tiene que ver con las posibilidades que tiene el niño de ver, leer, escuchar o interactuar con alguna fuente de información específica, de acuerdo con lo que mencionó el entrevistado.

Las fuentes intrapersonales son las más importantes respecto de la credibilidad, porque son ellos mismos los que experimentaron directa o indirectamente una situación de crimen. La vivencia generó en los participantes un conocimiento incuestionable, incluso cuando había espacio a interpretaciones. Así fue el caso de Abe (niño, MA-A), quien fue testigo directo de un robo en una tienda de conveniencia (es decir, estuvo presente al momento del incidente), y a pesar de no poder comprobarlo, estaba convencido de que el ladrón era un albañil.

Sin embargo, es importante reconocer que la frecuencia de exposición es la menor entre todos los tipos de fuentes, y así mismo, son menos accesibles. Es evidente que hay una intención constantemente activa en evitar ser víctima o testigo de algún incidente criminal. Se partió del supuesto en el que una fuente intrapersonal podría retar una visión hegemónica respecto de la violencia, y esto no fue así. Las imágenes de los delincuentes fueron similares a las descripciones ofrecidas por los dos niños testigos directos que compartieron su experiencia (Abe, niño, MA-A; Carlos, niño, MB): hombre, adulto, nivel socioeconómico bajo, moreno, con apariencia sucia. Es decir, a través de estas vivencias, reforzaron los discursos sobre los criminales, en cuanto a que el criminal es siempre hombre, pobre, con un fenotipo (estereotípico) claramente mexicano.

Las fuentes interpersonales tienen un papel intermedio en todos los aspectos, la falta de ellas resultó ser más creíble en comparación 
con los medios masivos; y en el caso de los participantes de testigos directos e indirectos, la familia, los amigos y las relaciones escolares, fueron el complemento más importante para comprender su experiencia personal.

No obstante, fueron pocos los informantes que percibieron estas fuentes como accesibles. En la mayoría de los casos, los niños indicaron que a los familiares y maestros no les gustaba hablar del tema o que era tratado como un tabú. Es decir, cuando hacían preguntas con el fin de aclarar dudas, los adultos respondían sin muchas explicaciones a sus dudas. Esto fue evidente al momento en que se trató de localizar participantes para el estudio, pues muchas instituciones y padres de familia rechazaron la autorización para que los niños fueran entrevistados. Además, son estos adultos quienes censuraron información masiva, pues cuando se presentaba frente a los niños algún contenido relacionado con el tema de violencia o inseguridad, los padres cambiaban el canal de la televisión a otros contenidos, o bien, escondían el periódico.

En el caso de amigos u otros compañeros de las escuelas o colegios, mencionaron que en general había desinterés o desconocimiento del tema. Si bien las fuentes interpersonales siguen siendo más accesibles que las intrapersonales, no fueron la principal fuente de información.

Las fuentes masivas que se exploraron y encontraron fueron las siguientes: periódico, radio, televisión (programas de ficción, noticieros, caricaturas, telenovelas), películas, videojuegos e Internet. Era de esperarse que los noticieros y periódicos representaran dos fuentes de información creíbles y frecuentes para este tema, puesto que su naturaleza no es solo representar la realidad objetivamente, sino que también su agenda estaba diariamente alineada a cuestiones de inseguridad en la ciudad, al momento del estudio.

En este punto, es importante recordar que no solo la agenda de los noticieros y periódicos se vio saturada del tema de crimen, sino que también las series de televisión, telenovelas y cine, tanto comerciales como independientes, se inspiraron en leyendas relacionadas al narcotráfico y al crimen organizado para generar narrativas. Dada la cantidad de contenido intertextual de dichas narrativas de ficción, el cual se basó en incidentes históricos asociados al crimen organizado, 
o en personajes fácilmente reconocibles del narcotráfico, la política y el clero mexicano, no fue sorpresa ver que los participantes también depositaron cierta credibilidad en este tipo de géneros que no están comprometidos a representar la realidad como los noticieros y periódicos.

Respecto de la frecuencia y la accesibilidad, los medios masivos son definitivamente los tipos de fuentes de información por excelencia. Inclusive las caricaturas han utilizado temáticas de crimen (sencillos como robos a casas, personas y bancos), razón por la cual no fue un tema ajeno o difícil de comprender.

En el caso de los que estaban familiarizados con videojuegos como GTA, les fue más fácil comprender los procesos de los delincuentes en la planeación y ejecución de un crimen. Posiblemente, el tipo de involucramiento que implica un videojuego en función de un contenido televisivo o cinematográfico es la principal diferencia entre el tipo de audiencias. En general, se identificaron más detalles o elementos inusuales en las historias y dibujos en los niños que mencionaron videojuegos; por ejemplo, mencionar que el jefe de los cárteles tiene su oficina en un stripclub, o que el crimen organizado trafica con diamante.

En tanto a la radio, no es una fuente a la que suelan acudir. Algunos participantes reconocen exponerse con frecuencia mientras viajan en coche o en autobús, pero no prestan atención y en ningún momento fue una fuente de información para sus representaciones sociales. Y finalmente, en cuanto al uso de Internet, todos tienen acceso a él, ya sea en sus casas o en la biblioteca pública de su colonia. Sin embargo, para fines de acceso a información sobre delincuencia, los niños suelen enterarse por medio de redes sociales (lo que publican sus conocidos), o a veces videos en YouTube. Más allá de eso, buscan tener acceso a los mismos contenidos que están disponibles en la televisión (series, telenovelas, filmes) o en periódicos.

Considerando los tres aspectos, el participante promedio obtiene la mayor información del tipo de fuente masiva, dado que hace una representación convincente de la realidad, lo cual la hace creíble, es accesible y, en definitiva, presenta de forma frecuente el tema de crimen y delincuencia. 


\section{CONCLUSIÓN}

Los puntos de encuentro entre la TRS y los estudios culturales de audiencia, se relacionan en cómo ambas teorías resaltan la importancia de los procesos comunicativos en la comprensión de la realidad del individuo, tal como se señaló en este artículo. Ambos reconocen que el papel de los medios de comunicación masiva es estructuralmente fundamental para la consolidación de una representación social, y por lo tanto, de acuerdos socialmente aceptados que se ven materializados en actitudes y conductas.

El estudio de representaciones sociales no puede evitar abordar a la vez el análisis de las representaciones que publican los medios en sus distintos formatos, géneros y narrativas. Los estudios culturales de audiencia, al investigar sobre la influencia que tienen los medios en la formación de actitudes, estereotipos e imaginarios, deberían acercarse a las representaciones sociales.

En función de la eficiencia del diseño metodológico, los entrevistados respondieron de forma positiva. Resulta relevante mencionar que ante circunstancias donde los niños no se sentían en un espacio adecuado para hablar abiertamente del tema de inseguridad, la gran mayoría se mostraron bastante dispuestos a discutir lo poco o mucho que sabían del tópico. Más de la mitad contestaron a todo con elocuencia y a veces con detalles, inclusive a las preguntas que no parecían comprender en su totalidad.

Las limitaciones de la sección de fuentes de información, como se mencionó en el apartado correspondiente, están relacionadas más bien con memoria, la cual se pudo haber visto afectada por el nerviosismo experimentado por algunos de los participantes. Sin embargo, no se detectó ninguna debilidad digna de mencionarse en el diseño del cuestionario o la dinámica de la entrevista.

Finalmente, el análisis permitió extraer tres características que resultan importantes al momento de hacer un comparativo de relevancia entre fuentes de información: la credibilidad, la accesibilidad y lo reciente de la exposición a esa fuente. En definitiva, son tres factores que deben ser tomados en cuenta cuando se estudian fuentes de información de diferentes tipos (como en el caso de este estudio, que fueron clasificadas en intrapersonales, interpersonales y masivas). 
Existe una necesidad, tanto desde la TRS como de los estudios culturales, de ubicar el papel de los medios de comunicación como fuente de información del individuo. La clasificación de fuentes en las tres categorías (intrapersonales, interpersonales y masivas) puede ser utilizada en otros estudios, pues engloba las distintas interacciones de información que puede tener un individuo en su relación con los diferentes álteres.

Las fortalezas de los estudios que buscan una perspectiva holística de estas interacciones son precisamente que gracias a ello se descubren significados que se depositan en cada una de las fuentes. Estos significados variarán dependiendo del objeto de la representación social que se esté explorando. En el caso de inseguridad y delincuencia, es importante recordar lo que Jovchelovitch (2001) mencionaba respecto de que las representaciones sociales se usan para reducir el sentimiento de amenaza en una situación de conflicto, como lo es la presencia del crimen organizado en una sociedad.

Así mismo, es importante el tratamiento que le da cada formato y género mediático al objeto de la representación social. El caso de la inseguridad provoca confusión porque, como se indicó previamente, inclusive las narrativas de ficción le daban un sentido "realista" a las representaciones. El carácter polisémico de los diversos mensajes mediáticos genera de forma inevitable, una amplia gama de interpretaciones en sus audiencias, aunque se sostienen dentro de un marco que promueve estereotipos, generalizaciones, actitudes, sentimientos y formas de comprensión.

\section{Referencias bibliográficas}

Araya, S. (2002). Las representaciones sociales: Ejes teóricos para su discusión. Tesis doctoral no publicada. Facultad Latinoamericana de Ciencias Sociales y Agencia Sueca para el Desarrollo Internacional, Costa Rica.

Atoms, M. (Guionista). (2003). The grim adventures of Billy and Man$d y$ [Programa de televisión]. EE.UU.: Cartoon Network Studios.

Barker, C. (2008). Cultural Studies. Theory and Practice. Londres: Sage Publications. 
Bar-Tal, D. \& Teichman, Y. (2005). Stereotypes and prejudice in conflict. Representations of Arabs in Israeli Jewish society. Cambridge: Cambridge University Press.

Inzunza Acedo, B. (2014). El bueno, el malo y el niño. Representaciones sociales sobre inseguridad y delincuencia en niños de San Pedro Garza García. Tesis doctoral no publicada. Tecnológico de Monterrey, México/Universidad de Amberes, Bélgica.

Jovchelovitch, S. (2001). Social representations, public life, and social construction. En K. Deaux \& G. Philogène (Eds.), Representations of the social (pp. 165-182). Oxford/ Malden: Blackwell.

Lara, A. (Director) \& Romero, J. (Productor). (2010). El Bazucazo [Película]. México: JS Films.

Lemish, D. \& Götz, M. (2007). Introduction. Studying children and media at times of war and conflict. En D. Lemish \& M. Götz (Eds.), Children and media in times of war and conflict (pp. 1-12). Cresskill: Hampton Press.

Moscovici, S. (2001). Social representations. Explorations in social psychology. Nueva York: New York University Press.

Orozco, G. (1991). La mediación en juego. Comunicación y Sociedad, 10-11, 107-128.

Wagner, W. \& Kronberger, N. (2001). Killer tomatoes! Collective symbolic coping with biotechnology. En K. Deaux \& G. Philogène (Eds.), Representations of the social (pp. 147-164). Oxford/ Malden: Blackwell. 